\title{
INCENSE AND INCENSE STICKS: TYPES, COMPONENTS, ORIGIN AND THEIR RELIGIOUS BELIEFS AND IMPORTANCE AMONG DIFFERENT RELIGIONS
}

\author{
Virendra Kumar Yadav1, Nisha Choudhary2, Samreen Heena Khan², Areeba Khayal3, Raman Kumar Ravi4, \\ Pankaj Kumar', Shreya Modi2, G. Gnanamoorthy ${ }^{5}$
}

1School of Lifesciences, Jaipur National University, Jaipur, Rajasthan 3002017, India

2School of Nanosciences, Central University of Gujarat, Gandhinagar, Gujarat-382030, India

3Department of Chemistry, Industrial Chemistry Section, Aligarh Muslim University, Aligarh, UP, India

4School of Environment and sustainable development, Central University of Gujarat, Gandhinagar, Gujarat-382030, India

6Department of inorganic chemistry, University of Madras, Guindy Campus, Chennai, T.N.-600025, India

Email id: yadava94@gmail.com

\begin{abstract}
Incensing (incense stick burning) is an ancient tradition during different rituals in almost every religion. Earlier, it was used explicitly for divine purposes only. However, with the advancement of time, it is being used for secondary purposes, such as air fresheners and insect repellant. Incense sticks burning hold an important place in Hinduism, Christianity, Buddhism, and Islam. All religions have their own belief behind the usage of incense sticks. Peoples from different countries, use incense of different sizes and flavors at various occasions. The tradition of incensing and incense stick burning is not new to our society. Peoples are using incense sticks since ancient times on different occasions in different forms. The passing time has brought various changes in the ingredients, functionality, manufacturing, and burning methods of the incense sticks. Today, the incense sticks are not only limited to fragrance purposes but also used as air fresheners and insect repellants. All religions have their own beliefs for the usage of incense sticks.
\end{abstract}

Keywords: Incense; Incense sticks; Hinduism; Buddhism; Bakhoor 


\section{INTRODUCTION}

Incense is an aromatic biotic material that releases fragrant smoke on burning [1]. Incense is accessible in different shapes and sizes around the globe [2]. The incense is usually made up of fragrant materials combined with a flammable binding material [3]. There are several materials which are used from ancient times either in combination or alone for incense. Such type of materials are aromatic woods, herbs, resins, and essential oils [4]. It was especially used to eliminate the bad odor, negative energy from the surroundings and filled with positive energy [5]. Moreover it was also used for worshiping the deity in different religions around the world. Nowadays, it is being used as an insect repellent i.e. mosquito repellent [6], meditation and aroma therapy [2]. The application of incense for deity purposes is available in all the ancient literatures. Today, incense is used at all the religious places, including churches, temples, mosques, and other religious places [2]. The incensing is performed by burning the incense material in different forms like powder, rope, coil, paper etc. and different perfumes [7]. Today, incense and incense sticks market are spread around the whole world. The major countries that uses and exports incense and incense sticks are USA, Brazil, China and India [2]. The market of China and India has increased drastically in the last few years due to high demand and production inside and outside their countries. Different religions have different beliefs for burning of incense and incense sticks and incensing at all the events have become a common practice. There are several literatures which suggests the origin of incense and incense sticks either from China, India or Egypt [2]. Though their use is mentioned in all the religious book of all the religions. Here, in the present review, insight on the various forms of incense and incense sticks in the market has been provided. Here we have also tried to provide a vision on the beliefs about lighting the incense and incense sticks among different followers of religion. We have also tried to put light on their composition and importance and origin.

\section{Classification of incense sticks on the basis of burning}

Broadly, based on their shape and size, the incense burning could be classified into two groups [8-10]. One is direct burning where the incense and incense sticks are combusted directly by using fire. While second method is placing the incense and incense sticks on a heating object like heater or other such types of devices. The preferences of the direct and indirect burning of incense depends on the culture, personal choice, and tradition [11]. The production of direct or indirect burning incense is manufactured in order to provide a pleasant smell in the environment [12, 13]. However, the composition of both direct and indirect incense differs due to the previous prerequisite for stable and sustained burning. Direct burning incense is burned independently of anyone, rather than heat or fire from an external source. For directburning, the incense's tip or end is ignited 
with a fire until it begins to transform into ash at the end of the burning. Flames on the incense are then blown out, with the incense proceeding to burn without a flame on its own. Backhanded consuming incense is a blend of fragrant fixings that are scorched over a warm source. Indirect burning incense, bits of the incense is signed by putting them over a heating element or onto a hot metallic plate in a censer or thurible [14]. Both the processes of burning of incense and incense sticks are given below in detail [2].

\subsection{Indirect-burning Incense and Incense Sticks}

Indirect-burning incense, also known as "non-flammable incense", is a mixture of fragrant materials like resins [15]. They do not contain combustible materials that require different burning sources. This fragrance can be different from the burning time of the surface of the material. The more delicate fragrance components tend to burn faster due to larger surface area than coarser or thicker fragrances with smaller surface areas [16]. The burning of incense sticks in such type of incense and incense sticks are usually is ensured by charcoal or coal powder $[2,10]$.

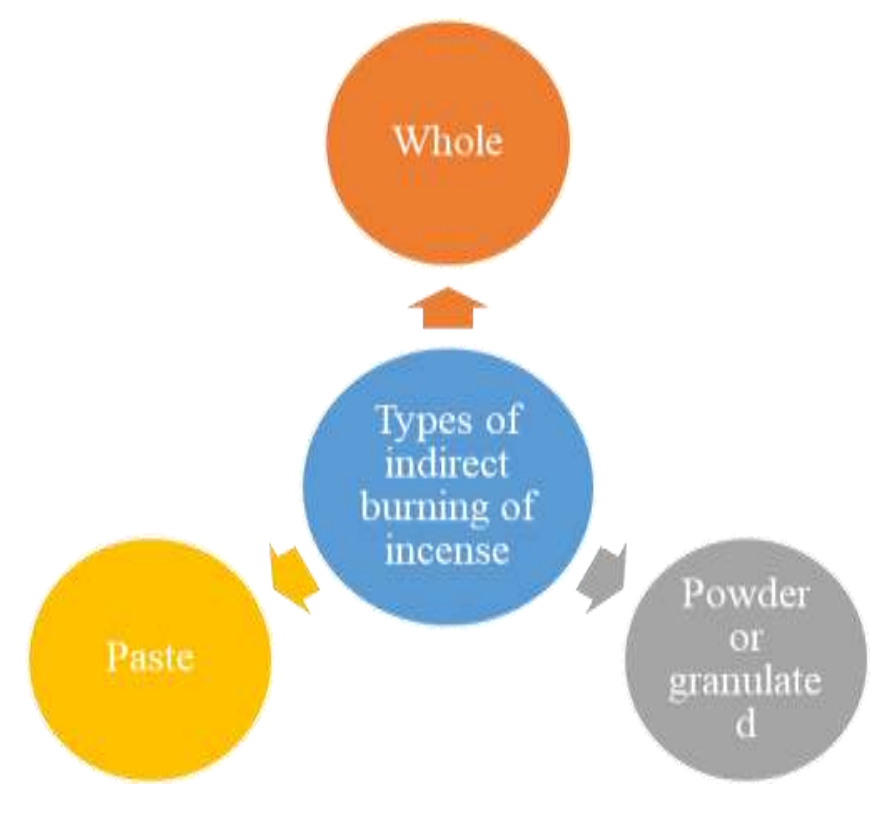

Fig.1 Types of indirect burning of incense sticks

While the indirect burning of incense sticks and incense, is further alone categorized into three types; whole, powdered or granulated and paste [10] which is shown in the Fig 1. In the whole form of incense, the fragrant material is directly burned in its crude natural form over coal embers
[17]. Whereas, in powdered or granulated one, incense material is converted into finer particles that help in the burning process quickly into better pieces. This fragrance is consumed rapidly and produces strong smells in a short period of time [10]. 
While, the powdered incense material is combined with a sticky and incombustible binder such as honey, dried fruits, and resin transformed into balls or little pastilles. They can be developed in a controlled atmosphere in which the fragrances can be mixed and combined [4]. The best example of granulated or powdered incense are "Bukhoor" or "Bakhoor," which are especially a type of Arabian incense [18]. Similar kind of incense material is also used by the Japanese people which is marked by a kneaded incense, called nerikō or awasekō [19, 20]. While, such type of incense i.e. fine powder or grounded is also used by the Eastern Orthodox Christian Convention (EOCC). In such type of incense, crude frank incense [21] is crushed into fine granules which is further mixed with different sweet-smelling essential oils [22].

\subsection{Direct-burning of incense and incense sticks}

The direct burning incense is also known as "combustible incense" [23], is directly ignited by fire. The shiny embers on the incense burner will continue to smolder the incense burner without the application of outside heat or flame source [24]. In the direct burning incense or incense sticks, the incense is either expelled, pressed into a structure, squeezed, or coated with supporting material $[2,25]$. This type of fragrance is produced from a moldable substrate that uses an aromatic finely ground (or liquid) fragrance material and an odorless adhesive [26, 27]. The composition of such types of direct incense burning must be changed to produce a suitable fragrance of proper concentration for smoother burning. The demarcating features about the direct-burning incense is that the incense material itself can take virtually any shape, as indicated by utility [28]. Out of direct burning some of the most common types are the coil ones, which are extruded and formed into a loop-shaped without a base [5, 10]. This incense can burn for a more extended period, from hours to days, and is usually delivered and utilized by Chinese culture [29]. Besides, coils, there are cones also which falls in this family of direct burning of incense [10]. Incense belonging to the direct burning, burns rapidly in comparison to the indirect or other type of incense burning. Such types of incense were initially designed in Japan in the 1800s. Another member in this family is cored sticks; where such type of incense sticks has a supporting core of bamboo [30]. The higher quality of such cored sticks has a fragrant sandalwood base which in turn is covered by a thick coat of incense material that burns with the core's smoldering heat. This kind of incense is generally produced and widely used in India and China [15]. Sometimes the cored sticks is also called as joss sticks in Chinese folk prayers [31]. Solid sticks also belongs to the direct burning of incense and incense sticks where such types of incense sticks has no supporting core and is made of incense material $[32,33]$. Such solid sticks, are designed such that it could be effortlessly broken into fragments, it enables one to decide the particular length of incense they wish to burn. These are the most commonly used incense in Japan and Tibet. Powdered form of 2020 November Edition | www.jbino.com | Innovative Association 
incense from this class is considered unique as these are free incense powder form and used for making indirect incense so that it can be burned at anyplace without any further modifications [34]. Both, Japanese and Tibetans used to prepare a long solid incense. Besides all above there are paper type of incense and incense sticks also in this family which are infused with incense, collapsed accordion-style, ignited, and combusted out [2]. While in the rope type of incense [10], incense powder is moved into paper sheets, converted into rope, entangled firmly, grown at that point, and bent again, creating two strands of rope [5]. The larger end of such rope type of incense has harbour or inlet which could be kept vertically in a shallow stone dish and the pointed end is used as lit. This kind of incense could be easily transported to larger distance by keeping them fresh for a prolonged period. Rope type of incense was especially used in the countries like Tibet and Nepal for a considerable period [5]. "Joss" is another type of direct incense burning, which is derived from the Latin word, 'Deus' (God) and is derived from the Portuguese 'deos', Javanese' dejos. Joss are also lighted at sanctuaries crosswise over several parts of East, South, and Southeast Asia [35].

From, the above sections, now it is clear that there are various incense forms, including sticks, joss sticks, cones, coils, powders, rope, rocks/charcoal, and smudge bundles [5]. The main difference between the first two forms is that the former has a slender bamboo base where the mixture of incense ingredients is attached, while the latter is without a central base [10]. Among all the above types of incense, direct-burning incense are very common in India [10].

The term incense refers to the substance itself, not to the smell it produces [36]. Incense comes from tree resins and some flowers, seeds, roots, and barks that are aromatic [37]. The perfume originated from incense shows in the word itself, i.e., 'per' and 'fumum' means through and smoke or fumes in Latin [21]. Incense is composed of aromatic organic materials which release perfumed smoke when it is subjected to burn. Incense sticks, a word that in itself creates an aura of fresh aroma and a fragrance leading to a relaxed feel to breathe. The incense stick is cylindrical with a bamboo base and a mixture of incense for worshipping gods and other rituals in houses and religious places [38]. Incense sticks are used to purify the bad air and fill the environment with pleasant fragrance and positive energy. It is believed in most of the religions that the holy smoke resealed from such incense sticks that prevents unwanted negative energy and an evil spirit from entering home [12, 38].

People of different religions around the globe uses incense sticks in their daily life for worshipping the deity. Based on the geographical area and languages, it is known with different names such as "agarbatti" in India [39], joss sticks in China and other South Asian countries [40], and "bakhoor" in Arabic countries [27]. In India, incense sticks are utilized from the ancient period for religious purposes. Indian incense sticks have a slender bamboo base onto which the mixtures of incense ingredients are attached [12]. The average dimension of Indian incense sticks is 15-19 
$\mathrm{cm}$ in length of bamboo and diameter of $0.4 \mathrm{~cm}[2]$.

\section{Types of incense sticks: based on the source of composition}

Based on the source of compositional origin, incense sticks can be either synthetic or natural [2]. Natural incense sticks are sticks that are coated with materials naturally obtained from nature. The natural incense sticks are considered as gift for God, don't leave any residue, and are harmless to an individual [2]. It has therapeutic effect on the devotees as it fills the environment with fresh air which helps in to relax in harmony with nature. These natural incense sticks produce a pleasing aroma to ensure that the home is not choked with undesirable smoke by maintaining the fragrance level liked by everyone [10]. Some of the significant natural incense sticks ingredients are; sandalwood, mogra, and musk [10]. Sandalwood is a class of wood which is obtained from trees; incense sticks usually have essential oil from sandalwood. The sandalwood, as well as oil, have the aroma distinct to be accepted for centuries. The fragrance released from sandalwood coated sticks marks a religious significance and is believed to act as an antiseptic [41]. While the second one is mogra, which is a flower predominantly found in India, is a natural source in incense sticks. It is believed that the mogra flower has a soothing and long-lasting aroma without producing a harmful matter to breathe in. The fragrance has an aesthetic appeal and involves no artificial ingredients or polluting agents in its composition. The third one is musk type where such fragrance has been used as a base note in several incense sticks. It is also an excellent fixative, which minimizes the evaporation rate and allows the original composition to last longer by preserving its right fragrance.

\section{Types of incense sticks based on the origin}

Based on the origin, incense sticks could be categorized broadly into Western incense and Eastern incense [42]. The incense stick is used western churches comes almost exclusively from the gum resins in tree bark. These resin pieces, called grains, are easy to carry and release their fragrance when they are sprinkled on burning coal [43]. While the Eastern incense is processed from other plants for instance sandalwood, patchouli, agarwood, and vetiver [10]. These plants and their parts are harvested and ground using large mortar and pestle and water is added to make a paste. A potassium nitrate is mixed in it to help the material burn uniformly [5].

\section{Raw materials and composition of incense sticks}

The incense sticks business depends intensely on forest items for raw materials. Manufacturing of incense sticks doesn't involve any complex synthetic substances and raw materials. The various components which are necessary for the manufacturing of incense sticks are as follows: nargis powder, raw bamboo sticks, water, variety of oils, aromatics including flower essence, sandalwood oil, rose petals, natural as well as chemical aromatic ingredients, sawdust, thick paper, gelatin paper, scissor, waste paper, various color powder, charcoal and sticky powder such as Jigat,Sal gum, Guggul (Gum/gum 
of Commiphor amukul) [2, 12]. The stick of incense is manufactured from "bamboo sticks" and fragrance oils whereby both the component and natural material. Through in India, the sticks are imported and produced of bamboo from China. A paste formed of sawdust through machine wood, a sort of hardwood, is covered with the upper part of each stick. The sawdust is extremely permeable and holds perfume easily. Charcoal is often employed to manufacture the permeable punk, and in incense sticks manufactured in India, it is preferred [38].

The aromatic oils are derived from the oil through naturally aromatic plants or several other perfumes including fragrances that are blended together in an oil base. Probably depends on the smell, small amounts of paint have been used to color-code the ends of the incense sticks Aromatic ingredients (oils), both natural and chemical, are used to add aroma in incense sticks.

\subsection{Jigat}

Jigat is an essential element for the making of agarbatti. It can be separated by peeling of barks of tree species like Litsea chinensis (Syn. Litsea glutinosa), Machilus macaranthatrees in the Coorg and Maland districts of tropical wet evergreen forests in Karnataka state of India. [44, 45]. The availability of the binding material for masala incense sticks seems to have emerged a major problem for the manufacturers of incense sticks. Currently, jigat obtained from the glutinous bark of Persea macrantha is mainly used by the manufacturers [45]. Jigat is a vernacular word signifying "sticky" that is used in the Karnataka province of India. Currently, 50 percent of the demand for Jigat is accomplished by importing the material from Malaysia and Thailand. According to All India Agarbatti Manufacturer's Affiliation (AIAMA) estimate, the current interest for Jigat is about 10000 tons per year.

\subsection{Bamboo}

In the Indian market, the raw material needed for the production of incense sticks is widely accessible at a low cost [2]. Bamboo sticks are another key raw material required for the business. The center of the incense sticks is produced of a split, cut, and measured bamboo which are of two categories: square and a round part, each roughly $1.5 \mathrm{~mm}-2 \mathrm{~mm}$ and $3 \mathrm{~mm}$ thick, and in lengths of either 8" $(203.2 \mathrm{~mm})$ or 9" $(228.6 \mathrm{~mm})$ [2]. The industry utilizes around 208 billion bamboo sticks every year. The bamboo stick's expense is just about $1 \%$ of that of the finished incense sticks [2]. The base material of the Incense sticks is bamboo, widely accessible on the Indian market and transported from China and Vietnam.

\section{Composition of incense and incense sticks}

The contents of incense are secrets and vary from one manufacturer to other, but mainly it has fragrant gums, resins, wood powders, herbs, and spices, shown in Fig.2, in the following compositions:-

1) Herbal and wood powder 21\%: (coal powder and sawdust)

2) Fragrant materials $35 \%$ traditionally would be a masala (powder of ground ingredients) [2].

3) Adhesive powder 11\%: or pastegenerally made of charcoal dust or sawdust and joss/jigit/gum/tabu powderan adhesive made from the bark of Litsea 
glutinosa and other trees) [2]. In India, wood glue called patta or bummi powder or jigat powder is used.

4) Bamboo sticks 33\%: by weight and generally have two different sizes, 7 " and 10 " inches.

Moreover, Indian incense stick manufacturers add $40 \%$ calcium phthalate

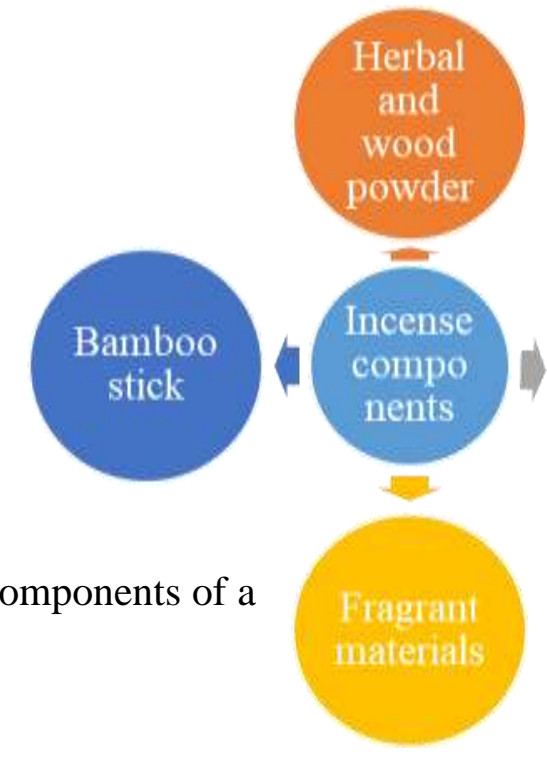

Fig. 2 Components of a

Incense sticks of about $75 \%$ are prepared of the modest quality containing just charcoal powder or low-quality sandalwood powder with a blend of $50 \%$ of "wood gun" powder [12]. Essential oils, refined resins, natural fixatives such as amber, musk, and civet are available together with synthetic aromatics in advanced varieties.

\section{Evolution of incense and incense sticks in world}

Throughout the ancient century, the emergence of the incense sticks could be attributed to the burning of aromatic wood. Since achieved by mankind these fragrant incense sticks played a vital role in regular rituals and became more religious [33]. In most of the popular world's
[38] to reduce the particulate matter and gaseous products formed during incense sticks' burning [38]. Since incense sticks are fully burned, 1/3rd ash by weight of the ash is formed. About $60-70 \%$ weight of incense sticks comprises of hazardous material.

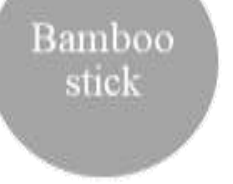

typical Indian incense sticks religions, incense has performed a key role. The ancient religions linked the natural world with their gods. It was claimed that fragrant plant materials forced demons away and allowed the gods to come on the earth; they also had the realistic application of exiling unpleasant smell. The Old Testament, the Vedas, and several other ancient books document the consumption of incense sticks [46]. Incense sticks have been extensively found in various worship places since prehistoric times, such as churches, monasteries, mosques, and temples. During celebrations, ceremonies, and several everyday rituals in which it is said to worship ancestors, the Hindu, Buddhist, Taoist, and Shinto religions everyone use incense [47]. 2020 November Edition / www.jbino.com | Innovative Association 
Incense has been commonly seen in countries namely Greece, Japan, Egypt China and India throughout prehistoric days. Different countries have different beliefs about incense usage in other places, purposes, and events [22]. For instance, in India, the incense sticks usage includes worshipping the deity as it is considered a valuable greetings to the idols [48]. In addition, it is often assumed that the burning of incense as well as sticks of incense occupies the environment with divinity, which would be a tool for comfort and pureness of the mind. In moulds and burn-in designs, the Egyptians used to manufacture cosmetics and perfumes of incense combined with oils or unguents and mixed fresh herbs assumed to deliver better prosperity. During prayers and ceremonies to visualize the gods, the Babylonians used incense; their preferences were resins from cypress, oak, and pine trees. While exorcisms and for rehabilitation, they often depended on incense[47]. Before the Babylonian exile (586-538 B.C.) they introduced incense into Israel; and since, both during the exile, incense has been part of ancient Jewish worship. In order to scare away spirits and to satisfy the gods, both the romans and Greeks employed incense. The ancient Greeks practiced many sacrificial rites and gradually started supplementing live offerings for the burning of incense. In South Asian countries, such as Japan, China, and Burma, incense as well as sticks of incense have a specialized purpose.

The custom of incense in Japan involved specific racks to hold kimonos, so that the smoke from burning incense could penetrate these folds of clothing. The sideview mirrors have also been immersed in incense fumes to subtly smell the fur. Clocks were created of sticks of incense; various scents from the sticks alerted those monitoring the time of the shifting hours. Incense was also used by the Chinese for different purposes, namely scenting clothing, fumigating books to eliminate bookworms, and scenting inks and documents. Sometimes the fan (an import from Japan into China) was made with sandalwood forming the ribs, so the movement of the fan would disperse the wood's fragrance. Further the Western Catholic Church and the Eastern Orthodox Church employed incense in services and ceremonies during Christianity. Incense has often been introduced more intensively in Eastern services.[14].

\section{Incense sticks and religious beliefs in different religions}

Since ancient times, the incense burning and incense sticks is practiced by every religion and this custom is followed even today. In the world of technology, companies have also started various modified incense sticks in terms of aroma, flavor length, or e-incense sticks. Numerous companies have also come up with new incense ash collectors. From all the evidence, it is concluded that incense and incense sticks find a unique role in every religion that has been discussed in present review.

\subsection{Hinduism}

In Indian culture, incense sticks is recognized with lots of importance, all religions in within India use incense for worship purposes. The natural aromas of the incense can help to improve the mood and allow our minds to focus. It holds and allow our minds to 
specific importance within Hinduism, as incense sticks has been considered as a vital part of any Hindu custom. As in Hindu faith, no prayer session is properly accomplished despite using these soothing fragrant sticks. All Hindus are all familiar with the divine fragrances of the incense sticks. The ritual of burning incense is incredibly symbolic in Hinduism. Incense has now become an aroma that is synonymous with Indian culture. The brightly colored sticks and infatuating scents can be found all over the country from temples to households. During the ceremonies, the stick of incense is ignited to expel the unpleasant smell from the air. It provides an ideal environment for promising habits by emitting a pleasant scent in the air. When they emit fumes, they also work as organic disinfectants. It has some psychological advantages also, as the incense stick's fragrance has a healing power that soothingly has a positive effect on the mind. The calming impact relaxes the brain and aids in performing rituals with a better concentration in the prayers, which are offered with a calm mind that acts as a meditation process [49].

The worshipers also display their reverence for the "Panch Bhutas", namely Earth, Water, Fire, Air, and Space, by lighting this spiritual stick. Bamboo and bamboo sticks are not found appropriate in Hinduism and are seldom used to produce incense sticks. The bamboo method originated in India even, as they do not use a bamboo core, is distinguished from Nepal, Tibet, and Japanese stick-making methods. Though the technique is employed in the west, particularly in America, it is strongly 2020 November Edition / www.jbino.com | Innovative Association associated with India. Incense has its spiritual values. This custom indicates the human virtue of giving up oneself for society [2]. In Hinduism, the incense sticks are utilized as air fresheners amid typical days and an integral part of every Hindu ceremony.

\section{2 Christianity}

Christians, and before them, Jews started incense sticks used as part of their religious practice. A popular view in the late 1800s strongly argued the use of incense sticks to cover smells and prevent disease. Modern theories suggest that incense remembers a time of sacrifices, a part of religious expressions that symbolizes God's incorruptibility. The transformation of resin to smoke illustrates the change from the body to the soul. The act of "incensation" or "thurification" is an unspoken way to express the blessings of God, which comes upon them who approach him in the proper attitude of being unworthy of even raising eyes to heaven [36]. Early Christian churches used incense during the Eucharistic ceremony, in which it symbolized the ascent of the prayers of the faithful and merits of the saints. Later, incense was employed sporadically in the Church of England and used during divine worship, and processions have been continued [12].

Incense has been used by many Christian gatherings since ancient times, especially in the Roman Catholic and Eastern Customary holy places, yet also in Anglican and Lutheran Holy places. Incense sticks might be utilized in Christian worship at the Eucharist festival, and at grave festivals of solemn celebrations of the Divine Office, particularly at Solemn 
Vespers. Several incense formulations are presently utilized, regularly with frankincense, myrrh, styrax, and copal or different aromatics. The smoke of burning incense is seen by a considerable lot of the Roman Catholic and Eastern Orthodox faith as an indication of faith prayer. By the fourth century A.D., the early Christians had incorporated incense burning into their practices, particularly the Eucharist when the ascending smoke was thought to carry prayers to heaven. They use a thurible, i.e., a kind of censer, for collecting the incense as it is burned. A server called a thurifer, sometimes helped by a "boat bearer", approach the individual directing the administration with a thurible with burning charcoals. Incense is taken from what is known as a "boat" and is generally honored with a prayer. The thurible is then closed and accepted by its chain and swung towards the individual or thing being incensed. Grains of favored incense is put in the Easter flame and the mausoleum of blessed sacrificial stones

\subsection{Importance of incense sticks and incense in Jews}

Ketoretwas the incense offered in the Temple in Jerusalem and is stated in the Book of Exodus as a mixture of stacte, onycha, galbanum, and frankinc ense [21].

\subsection{Importance of incense sticks and incense in Islam}

Incense burners were no novel vessels brought to meet Islamic social life. Although on a fundamental level, as opposed to luxurious lifestyles, Islam does not forestall incense utilization. During the main hundreds of years, the prominence incense is best shown by the prolonged legalistic feelings communicated in the Hadith writing [50]. The significant utilization of incense was not without impact upon Islamic individuals' business exercises. The incense burner is now and again distributed piece in the Islamic Department of the Staatliche Museen in Berlin, which is said to be found in the remnants of alRayy. Burning Arabian incense (Bakhour) is a typical practice in the Middle East and Arabian Gulf. All prophets used Bakhour and the prophet Mohammed (S.A.W.) and his companions regularly and mostly on Fridays. This tradition was started in Arabia and subsequently spread in the vast territory of the Muslim world. It is believed that the Holy Prophet said, "agarwood is a trenchant item of paradise. He also divulged the various healing properties of agarwood, specified to Hindi Oud, and its efficacy in treating pleurisy. It is used to Purify Kaaba and the Tahfidh graduation ceremony. As claimed in Hadith of Prophet, Angels love incense smell and hate repugnant odor. Bakhour is usually fume in a Mabkhara (traditional incense burner), accustomed in several Arab countries to pass Bakhour during majlis, particularly on Jumma (Friday) or to await guests [51]. The incense burners brought in Arabic mijnmar for comparing the needs of different layers of refined social orders. Although Arabian incense is a typical social practice in the Arabian Gulf, especially inside the home, there is a significant hole of information about the substance of the smoke discharged into the environment [51]. Incense, Myrrha, is used for custom cleaning and to destroy the evil and antagonism. Numerous substances are utilized to create incense, 
including Oud, frankincense, aromatic wood, herbs, blossoms, fundamental oils, and fragrances. In most Arab nations, the most generally utilized incense is Oud, broadly used by numerous individuals [51]. The Oud tree is known as the Aquilaria agallocha, which has, at any rate, 15 types of Aquilaria and is otherwise called lignum aloe, agarwood, and hawk wood [52]. The fragrances of the agarwood known as Oud are essential in Saudi Arabia and the United Arab Emirates. Middle Eastern Oud is a characteristic indoor aroma, particularly in wedding parties and different functions [22]. It is likewise used to aroma dress and home and to terminate the tenuous smell of smoke, pet and cooking smell. Bakhour is one of the most well-known wellsprings of indoor smoke in the Arabian Gulf area. People are presented on a week by week premise in many homes [53]. Bakhour can shift in the arrangement, yet it ordinarily contains a wide assortment of regular fixings, such as agarwood, woodchips, musk, and sandalwood that are absorbed scented oils. In most Arab countries, incense is burned in scented chips or blocks called bakhoor, which is used specifically on weddings or on Fridays or generally to perfume the house.

\subsection{Buddhism, Taoism, and Shinto in}

\section{Asia}

Incense sticks are also termed as joss sticks, especially in East Asia, South Asia, and Southeast Asia [40]. Incense has played an important role in East Asian Buddhist services and rituals and those of Chinese Taoist and Japanese Shinto places of worship. The use of Incense use in religious ceremonies was first introduced in China.
In the long run, it shifted to Korea, Japan, and Vietnam. Incense burning is a typical Chinese religious custom in Chinese culture, along with Taoism and Buddhism. It is considered a technique for decontaminating the environment and delivering the Buddhist Alamkaraka (Realm of Adornment). In Chinese Taoist and Buddhist temples, the internal spaces are scented with thick coiled incense, either dangling from the roof or on unique stands. Worshipers at the temple's lights and burn incense sticks in substantial packs, which they wave while bowing to the statues or plaques of a God. Individual stick of incense is then vertically put into individual censer situated before the statues or plaques either independently or in threes, depending upon the status of the divinity or the person's sentiments.

9. Origin and history of incense and incense sticks in different parts of the world 9.1 History of incense sticks in India Indian Ayurveda medical system has given the base of the current and the most sorted out method for the incense sticks making system, and that is still in practice. The Rig Veda and the Atharva-Veda are held as excellent sources to gather insights regarding the old history of incense sticks. The first phase belonging to Ayurveda manages the utilization of medications, where incense was used as a therapeutic tool for healing purposes. During that time, Hinduism understood the noteworthiness and made full utilization of incense, and continued to turn into a piece of Buddhism in India [54]. During that time, the status of the Indian incense was achieved an invaluable position. It was the incense sticks that met the source to reach China. 
As, per the facts, the Buddhist priests were the principal experts around 200 CE. They obtained the method of incense production in the beginning periods [9].

\section{2 History and origin of incense and incense sticks in China}

For over two thousand years, the Chinese have used incense in religious ceremonies, ancestor veneration, traditional Chinese medicine, and daily life [55]. With the introduction of Buddhism, China came calibrated incense sticks and incense clocks [55]. Incense stick burning is an everyday practice in traditional Chinese religion. Among ethnic Chinese and Chinese influenced communities, incense stick is burned traditionally before a home or business threshold, before the picture of a Chinese popular religion divinity or spirit of place, or in small and humble or large and elaborate shrine found at the main entrance to every village [40]. Here, the God of the earth is entrusted with the hope to bring wealth and health to the village. They can also be burned in front of the door or window as a gift to heaven or spirit. In some areas of China, incense sticks are used as timing devices. The use of these aroma timers has spread from Buddhist monasteries to Chinese secular societies.

There are several types of incense sticks or incense used for different purposes or on festive days in China. The significant differences in Chinese and other countries' incenses are that the Chinese incense has variable shapes and sizes $[17,56]$. The Chinese prefer the process of extruding the incense mix through a kind of sieve to form straight or curled strands, like small noodles, that can then be dried and burned [57]. Extruded pieces left to dry as straight sticks of incense are called joss sticks [35]. Incense paste is also shaped into characters from the Chinese alphabet or into maze-like shapes that are formed. Many of them are long and thin and are of different colour like yellow, red, and, more rarely, black. Thicker sticks are used for special ceremonies, such as funerals. Spiral incense is also used regularly, which is found hanging above temple ceilings with long burning time [58]. The neighbouring countries of China including Taiwan, Singapore, or Malaysia, celebrates the Ghost Festival [59]. In such type of festival there is a tradition of lighting a large, pillarlike dragon incense sticks which in turn generate so much smoke and heat that they are only burned outside $[59,60]$.

The elemental composition of Chinese incense sticks is comprised of the two most essential ingredients i.e., agarwood (chénxiāng) and sandalwood (tánxiāng) [61]. Chinese incense sticks are generally used without aroma or only the slightest trace of jasmine or rose. It is the smoke, not the scent, which is essential in conveying the divine prayers to heaven. They are composed of the dried powdered bark of a non-scented species of cinnamon native to

Cambodia, Cinnamomum

cambodianum. Though they contain no sandalwood, they often include the Chinese character for sandalwood on the label, as a generic term for incense. Some Buddhists use highly scented Chinese incense sticks [9]. These are often quite expensive due to the use of large amounts of sandalwood, agarwood, or floral scents [55]. The sandalwood used in Chinese incenses does not come from India. Incense burners, which are 
containers made of metal or pottery, were first used in China as early as 2,000 B.C. and became an art form during China's Han dynasty (206 B.C.-220 A.D.) [62]. These burners had pierced lids to allow the smoke and scent to escape. The designs from this period through the Ming dynasty (1368-1644) became omate increasingly with smoke-breathing dragons and other imaginative creations.

\subsection{History and origin of incense and incense sticks among Tibetans}

Tibetan incense refers to a common type of incense found in Tibet, Nepal, and Bhutan. These incenses have a characteristic "earthy" scent to them. Ingredients vary from cinnamon, clove, and juniper, to Kusum flower, ashwagandha, or sahi jeera. Many Tibetan incenses are thought to have medicinal properties. Their recipes come from ancient Vedic texts that are based on even older Ayurvedic medical texts. The recipes have remained unchanged for centuries [10].

\subsection{History and origin of incense and incense sticks among Japanese}

In Japan, the ancient stories of aromatherapy include art, culture, history, and rituals. It is often in sharp contrast to some indistinguishable features from music, literature, and art. Incense burning may happen inside the tea function. The specialty of incense appreciation, or Kohdo [14], is mostly practiced as different forms of artistic expression in the tea ceremony, and generally inside a tea room of conventional Zen design. Agarwood (Jinkō) and sandalwood (Byakudan) are the two most basic and essential ingredients in Japanese incense
[22]. Agarwood is known as "Jinkō" in Japan, which deciphers as "incense that sinks in the water" because of the resin's weight in the wood. Sandalwood is one of the most calming incense ingredients and is perfect for meditation [2] and often also used in the Japanese tea ceremony [63]. Another essential ingredient in Japanese incense is kyara, which is also a kind of agarwood [19, 25]. Japanese incense companies' categorized agarwood into six types depending on the region obtained and properties of the agarwood [22]. In Japanese Shinto altars and Buddhist temples, the incense sticks are placed horizontally into censers on top of the ash since incense sticks commonly lack a supporting core center [9]. While there are several Buddhist sects of Japan which uses a censer called egōro, which are usually made of brass with a long handle and no chain. Here they don't use charcoal, rather uses makkō powder which is lit, and the incense mixture is burned on top [64]. This method is known as sonae-kō (religious burning).

\section{Conclusion}

Burning of incense and incense sticks is a common practice across the whole globe. In different religions and parts of the world incense and incense sticks are used in different forms i.e. varying from powder, cone, ropes, paper or sticks. Their size and shape might have varied in religion to religion and parts of the world but the aim was to worship the deity, elimination of bad energy and fill the environment with positive energy. While their recent modifications, they have been used as an insect repellant. From, the religious literature it has been found that incense 2020 November Edition | www.jbino.com | Innovative Association 
and incense sticks were used from ancient times only. The present review highlights the importance of incense sticks in religious processes across the world.

\section{REFERENCES}

Yang, T.-T., T.-S. Lin, and M. Chang, Characteristics of Emissions of Volatile Organic Compounds from Smoldering Incense. Bulletin of environmental contamination and toxicology, 2007. 78(5): p. 308-13.

2. Yadav, V.K., P. Kumar, H. Kalasariya, N. Choudhary, B. Singh, G. Gnanamoorthy, N. Gupta, S.H. Khan, and A. Khayal, The Current Scenario of Indian Incense Sticks Market and Their Impact on the Indian Economy. Indian Journal of Pure \& Applied Biosciences, 2020. 8(3): p. 627-636.

3. See, S. and R. Balasubramanian, Characterization of fine particle emissions from incense burning. Building and Environment, 2011. 46(5): p. 1074-1080.

4. Raut, A.B., A.N. Shah, S. Polshettiwar, and B.S. Kuchekar, Preparation and evaluation of antimicrobial herbal based incense sticks for fumigation against infectious bacteria. Journal of Chemical and Pharmaceutical Research, 201 1. 3(4): p. 707-712.

5. Jetter, J., Z. Guo, J. McBrian, and M. Flynn, Characterization of emissions from burning incense. The Science of the total environment, 2002. 295/(13)): p. 51-67.

6. Ritchie, S., C. Williams, and B. Montgomery, Field evaluation of New Mountain Sandalwood Mosquito Sticks and New Mountain Sandalwood Botanical Repellent against mosquitoes in North Queensland, Australia. Journal of the American Mosquito Control Association, 2006. 22(1): p. 158-60.

7. Hsueh, H.T., T.-H. Ko, W. Chou, W. Hung, and $\mathrm{H}$. Chu, Health risk of aerosols and toxic metals from incense and joss paper burning. Environmental Chemistry Letters, 2011. 10(1): p. 79-87.

8. Ji, X., O. Le Bihan, O. Ramalho, C. Mandin, B. D'Anna, L. Martinon, M. Nicolas, D. Bard, and J.C. Pairon, Characterization of particles emitted by incense burning in an experimental house. Indoor air, 2010. 20(2): p. 147-58.

9. Qin, Z., Y. Song, and Y. Jin, Green Worship: The Effects of Devotional and Behavioral Factors on Adopting Electronic Incense Products in Religious Practices. International journal of environmental research and public health, 2019. 16(19): p. 3618. 
10. Lin, T.-C., G. Krishnaswamy, and D.S. Chi, Incense smoke: clinical, structural and molecular effects on airway disease. Clinical and molecular allergy: CMA, 2008. 6(3): p. 3-6.

11. Sillar, B., Dung by Preference: The Choice of Fuel as an Example of how Andean Pottery Production is Embedded within Wider Technical, Social, and Economic Practices. Archaeometry, 2007. 42(1): p. 43-60.

12. Virendra Kumar Yadav, B. Singh, and N. Choudhary, Characterization of Indian Incense Stick Powders for their Physical, Chemical and Mineralogical Properties World Journal of Environmental Biosciences 2020. 9(1): p. 39-43

13. Elsayed, Y., S. Dalibalta, I. Gomes, N. Fernandes, and F. Alqtaishat, Chemical composition and potential health risks of raw Arabian incense (Bakhour). Journal of Saudi Chemical Society, 2016. 20(4): p. 465-473.

14. Moeran, B., Making Scents of Smell: Manufacturing and Consuming Incense in Japan. Human Organization, 2009. 68(4): p. 439-450.

15. Mukunda, H., J. Basani, H. Shravan, and B. Philip, Smoldering combustion of "incense" sticks - Experiments and modeling. Combustion Science and
Technology, 2007. 1796(6): p. $1113-$ 1129.

16. Sowndhararajan, K. and S. Kim, Influence of Fragrances on Human Psychophysiological Activity: With Special Reference to Human Electroencephalographic Response. Scientia pharmaceutica, 2016. 84(4): p. 724-751.

17. Wei See, S., R. Balasubramanian, and U.M. Joshi, Physical characteristics of nanoparticles emitted from incense smoke. Science and Technology of Advanced Materials, 2016. 8(1-2): p. 25-32.

18. Alabdouli, A., D. Alao, and T. Jiaganesh, "Bakhoored" recurrent carbon monoxide poisoning from burning incense. The Journal of Emergency Medicine, 2020. 58(5): p. 848.

19. Ota, K., Incense and Japanese Culture. Journal of Japan Association on Odor Environment, 2008. 39(42): p. 169-185.

20. Dalibalta, S., Y. Elsayed, F. Alqtaishat, I. Gomes, and N. Fernandes, A health risk assessment of Arabian incense (Bakhour) smoke in the United Arab Emirates. Science of The Total Environment, 2015. 511: p. 684691. 
21. Ben-Yehoshua, S., C. Borowitz, and L. Hanus, Frankincense, Myrrh, and Balm of Gilead: Ancient Spices of Southern Arabia and Judea. Horticultural Reviews, 2012. 39(1): p. $1-76$.

22. López-Sampson, A. and T. Page, History of Use and Trade of Agarwood. Economic Botany, 2018. 72(1): p. 107-129.

23. Abdulwahab, A., Arabian incense exposure among Qatari asthmatic children. A possible risk factor. Saudi medical journal, 2007. 28(3): p. 476-8.

24. Harrak, A., The Incense Burner of Takrit. Eastern Christian Art, 2006. 3: p. 47-52.

25. Takiura, K., A. Yamaji, K. Iwasaki, and H. Yuki, Analysis of Japanese incense sticks by gas chromatography. Bunseki kagaku, 1973. 22(7): p. 916918.

26. Višić, B., E. Kranjc, L. Pirker, U. Bačnik, G. Tavcar, S. Skapin, and M. Remskar, Incense powder and particle emission characteristics during and after burning incense in an unventilated room setting. Air Quality, Atmosphere \& Health, 2018. 11: p. 649-663.

27. Al-Rawas, O., A. Al-Maniri, and B. AlRiyami, Home exposure to Arabian incense (bakhour) and asthma symptoms in children: A community survey in two regions in Oman. BMC pulmonary medicine, 2009. 9(23): $\mathrm{p}$. 23.

28. Niebler, J., Incense Materials, in In: Buettner A. (eds) Springer Handbook of Odor. , J. Niebler, Editor. 2017, Springer Handbooks. Springer, Cham. . p. 13-14.

29. Tse, L.A., I.T.-S. Yu, H. Qiu, J.S.K. Au, and X.-R. Wang, A case-referent study of lung cancer and incense smoke, smoking, and residential radon in Chinese men. Environmental health perspectives, 2011. 119(11): p. 1641-1646.

30. Ino, H. and M. Ishikawa, On the Burning of the Incense Stick. Journal of the Meteorological Society of Japan. Ser. II, 1942. 20(11): p. 418423.

31. Lin, T.-S. and M. Shen, Trace Metals in Chinese Joss Stick Smoke. Bulletin of environmental contamination and toxicology, 2003. 71(1): p. 135-41.

32. Croxford, B. and D. Kynigou, Carbon Monoxide Emissions from Joss or Incense Sticks. Croxford, B. and Kynigou, D. (2005) Carbon monoxide emissions from joss or incense sticks. Indoor and Built Environment, 14 (34). pp. 277-282. ISSN 1420326X, 2005. 14((3-4)): p. 277-282.

2020 November Edition | www.jbino.com | Innovative Association 
33. Ramya, H.G., V. Palanimuthu, and R. Dayanandakumar, Patchouli in fragrances-incense stick production from patchouli spent charge powder. Agricultural Engineering International: CIGR Journal, 2013. 15: p. 187-193.

34. Lin, H.-Y., D.-J. Hsu, and J.-S. Su, Particle Size Distribution of Aromatic Incense Burning Products. International Journal of Environmental Science and Development, 2015. 6(11): p. 857860.

35. Siripanich, S., W. Siriwong, P. Keawrueang, M. Borjan, and $M$. Robson, Incense and Joss Stick Making in Small Household Factories, Thailand. The international journal of occupational and environmental medicine, 2014. 5(3): p. 137-45.

36. Kenna, M., Why does incense smell religious?: The anthropology of smell meets Greek Orthodoxy. Journal of Mediterranean Studies, 2005. 15(1): p. 51-70.

37. Suvachittanont, $W$. and R. Sangsirimongkolying, Raw Material Management of Community Incense Production through Sufficiency Economy Philosophy. Procedia Social and Behavioral Sciences, 2013. 91 (2013): p. 697-702.
38. Yadav, V.K., K.K. Yadav, G. Gnanamoorthy, N. Choudhary, S.H. Khan, N. Gupta, H. Kamyab, and Q.$\checkmark$. Bach, A novel synthesis and characterization of polyhedral shaped amorphous iron oxide nanoparticles from incense sticks ash waste. Environmental Technology \& Innovation, 2020. 20: p. 101089.

39. Yadav, V.K. and M.H. Fulekar, The current scenario of thermal power plants and fly ash: production and utilization with a focus in India. International Journal of Advance Engineering and Research Development 2018. 5(4): p. 768-777.

40. Staub, P., M. Geck, and C. Weckerle, Incense and ritual plant use in Southwest China: A case study among the Bai in Shaxi. Journal of ethnobiology and ethnomedicine, $2011.7(1)$ : p. 43.

41. Sarkic, A. and I. Stappen, Essential Oils and Their Single Compounds in Cosmetics-A Critical Review. Cosmetics, 2018. 5(1): p. 11.

42. Archier, P. and C. Vieillescazes, Characterisation of various geographical origin incense based on chemical criteria. Analusis, 2000. 28(3): p. 233-237.

43. Morikawa, T., H. Matsuda, and M. Yoshikawa, A Review of Antiinflammatory Terpenoids from the 
Incense Gum Resins Frankincense and Myrrh. Journal of oleo science, 2017. 66(8).

44. Jayaraj, R., P. Hazarika, N. Dutta, S. Biswas, and R. Dutta, Status of agarbatti industry in India with special reference to Northeast. International Journal of Advanced Research in Biological Sciences, 2018. 5(1): p. 173-186.

45. Mohammad, N., A. Dahayat, M. Yadav, F. Shirin, and S.A. Ansari, Genetic diversity and population structure of Litsea glutinosa (Lour.) in Central India. Physiology and molecular biology of plants : an international journal of functional plant biology, 2018. 24(4): p. 655-663.

46. Mochio, S., H. Matsuno, S. Miyagawa, C. Toyoda, H. Oka, and Y. Iguchi, A study of dysosmia in Parkinson's disease: a simple method using an incense stick. Journal of the Neurological Sciences, 2015. 357(1): p. e279-e280.

47. Grbić, M., N. Unković, I. Dimkić, P. Janackovic, M. Gavrilovic, $O$. Stanojevic, M. Stupar, L. Vujisić, A. Jelikić, S. Stanković, and J. Vukojevic, Frankincense and Myrrh essential oils and burn incense fume against micro-inhabitants of sacral ambients. Wisdom of the ancients? Journal of Ethnopharmacology, 2018. 219: p. 1-14.
48. Chakrabarty, S. and M. Ghosh, Factors Leading to Disposal of Toxic and Hazardous Sacred Waste and Its Effect on Urban River Contamination: Case of Adi Ganga, Kolkata, India, in Perception, Design and Ecology of the Built Environment 2020, Springer Geography. Springer, Cham.

49. Yeleti, B., R. Mohan, S. Sanjay, and K. $B$ T, Smoldering of incense stick under the influence of wetness and orientation. Vol. 2161. 2019.

50. Sabry, W.M. and A. Vohra, Role of Islam in the management of Psychiatric disorders. Indian journal of psychiatry, 2013. 55(Suppl 2): p. S205-S214.

51. Mesallam, T.A., M. Farahat, R. Shoeib, S. Alharethy, A. Alshahwan, T. Murry, and K. Almalkia, Acute effects of inhaling Oud incense on voice of Saudi adults. Annals of Saudi medicine, 2015. 35(2): p. 111119.

52. Wang, S., Z. Yu, C. Wang, C. Wu, P. Guo, and J. Wei, Chemical Constituents and Pharmacological Activity of Agarwood and Aquilaria Plants. Molecules, 2018. 23(2).

53. Naziz, P.S., R. Das, and S. Sen, The Scent of Stress: Evidence From the Unique Fragrance of Agarwood. 
Frontiers in plant science, 2019. 10: $p$. 840-840.

54. Penchala Prasad, G., G. Pratap, M. Neelima, and V. Satyanrayanashastry, Historical perspective on the usage of perfumes and scented Articles in ancient Indian literatures. Ancient science of life, 2008. 28(2): p. 33-9.

55. Habkirk, S. and H. Chang, Scents, Community, and Incense in Traditional Chinese Religion. Material Religion, 2017. 13(2): p. 156-174.

56. Chen, L.-Y. and C. Ho, Incense Burning during Pregnancy and Birth Weight and Head Circumference among Term Births: The Taiwan Birth Cohort Study. Environmental health perspectives, 2016. 124(9): p. 14871492.

57. Ok, N., The Incense and Culture of the Silla Period-Through reviewing examples of incense. The Historical Association for Soong-Sil, 2019. 42: p. 133-153.

58. You, Z., Folk Literati, Contested Tradition, and Heritage in Contemporary China

Incense Is Kept Burning. 2020, Bloomington, Indiana: Indiana University Press.

59. Khezri, B., Y.Y. Chan, L.Y.D. Tiong, and R.D. Webster, Annual air 2020 November Edition | www.jbino.com pollution caused by the Hungry Ghost Festival. Environmental Science: Processes \& Impacts, 2015. 17(9): p. 1578-1586.

60. Chan, S., 6. Heritagizing the Chaozhou Hungry Ghosts Festival in Hong Kong, in Chinese Heritage in the Making. 2018, Amsterdam University Press. p. 145-168.

61. Kao, W.Y., C.Y. Hsiang, S.C. Ho, T.Y. Ho, and K.T. Lee, Chemical Profiles of Incense Smoke Ingredients from Agarwood by Headspace Gas Chromatography-Tandem Mass Spectrometry. Molecules, 2018. 23(11).

62. WU, X., A. Hein, X. Zhang, Z. Jin, D. Wei, F. Huang, and $X$. Yin, Resettlement strategies and Han imperial expansion into southwest China: a multimethod approach to colonialism and migration. Archaeological and Anthropological Sciences, 2019. 11(12): p. 6751-6781.

63. Kumar, R., N. Anjum, and Y. Tripathi, Phytochemistry and Pharmacology of Santalum album L.: A Review. World Journal of Pharmaceutical Research, 2015. 4(10): p. 1842-1876.

64. Mohamed, R. and S.Y. Lee, Keeping Up Appearances: Agarwood Grades and Quality, in In: MOHAMED $R$. (eds) Agarwood. Tropical Forestry. 2016: Springer, Singapore. p. 149-167. 